\title{
Experimental and numerical study on the interactions between high velocity long-rods and steel-elastomer bulging armor
}

\author{
T Fras \\ French-German Research Institute of Saint-Louis (ISL), \\ Saint-Louis, France
}

\begin{abstract}
The discussed laminated steel-elastomer armor takes advantage of the rubber interlayer that deforms rapidly under an impact which causes a subsequent deformation, so-called 'bulging', of the side steel plates. It is observed that long and slender kinetic-energy projectiles made with a tungsten alloy tend to fracture disturbed by an asymmetric contact with the deforming plates. The numerical analysis accompanies the ballistic test complementing it by a detailed insight into the defeat mechanism. Based on the experimental and numerical investigation, the given study explains its physical background.
\end{abstract}

\section{INTRODUCTION}

Kinetic-energy penetrators (KEP, KE projectiles, long-rod projectiles) are an ammunition type designed to penetrate thick armors of battle tanks or heavy armored vehicles. A penetration potential of $\mathrm{KE}$ projectiles is increased by minimizing the projectile's diameter and maximizing its length and mass by an application of the densest metals, i.e. depleted uranium or tungsten heavy alloys (WHA). Accelerated to the impact velocities higher than $1000 \mathrm{~m} / \mathrm{s}$, such a projectile with the optimized geometrical and material properties brings a large amount of the kinetic energy upon a minimal area of the target, burrowing a deep cavity through its structure. To stop this threat, an armor have to be very thick, which is not an optimal protection solution since with an increasing armor thickness, the total weight of a vehicle increases, too. To improve the ballistic efficiency of a protection system applied against kinetic threats, the following defeat mechanisms are maximized: deceleration, fragmentation, erosion or deflection of a threat. These defeat mechanisms constitute the basis of design principles of modern armors mitigating KEPs, which belong to one of three groups: active, reactive and passive armors. In the reactive and active systems, a part of the armor is propelled against the incoming threat either at some distance away from a protected combat vehicle (active) or at the moment of an impact (reactive). An asymmetric impact destabilizes a striker inducing an angular momentum in it so that it can turn to high yaw before the contact with the target or be fragmented. Instead of using an external energy source (such as an explosive layer) to move the side plates against a threat, passive armors or non-explosive reactive armors (NERA) reuse the energy of an impact. The explosive interlayer is changed to another material, which enforces a rapid deformation of the side plates against the threat. Two steel or metal plates may sandwich then an elastomer or polymer liner.

${ }^{*}$ Corresponding Author: teresa.fras@isl.eu 
When struck by a jet, it changes its shape rapidly causing a localized bending or bulging of the side plates in the area of the impact. As the plates bulge, the impact point shifts with the plate deformation, increasing the effective thickness of the armor and destabilizing a kinetic threat. The bulging is a less powerful effect than the plate movement caused by a detonation in an explosive reactive armor. Thus, it offers a lower level of protection than a similarly-sized ERA. However, passive solutions are lighter, safer to handle and can be packed in multiple spaced layers, [1].

During high-velocity ballistic tests, possible techniques of observations and measurements are limited - usually, the initial and residual velocity is measured and a high-speed camera recording or a flash X-ray imaging follow an impact. Interactions between oblique armors and high-velocity KE projectiles during the penetration and perforation are complex and account for an extensive deformation and fracture of all components under high strain rates. For a more profound analysis of experimental investigations, numerical analysis is considered as a useful tool. In [2-3], it was shown that it was possible to reproduce numerically fractures of a tungsten long-rod projectile impacted by a moving oblique plate within a reasonable computing time, without an extremely fine mesh. It was numerically proven that a larger projectile fracturing was a result of longer interaction time with the plate and a thicker back plate. A discussion about KEPs fracture caused by the contact with a flying plate may be found in [4]. The proposed analytical model described an influence of the geometry, material properties and the projectile and plate velocity on a fragmentation tendency of the long-rod projectiles. The shape and motion of the residual projectiles were determined and the effect of the interaction was quantified in terms of changes in its length, velocity, momentum and kinetic energy. It was shown that the parameters of the largest influence on the disturbance of the projectile were the plate thickness, its velocity and the movement direction. The influence of the nose shape on the interaction between long-rod projectiles and oblique plates was studied in [5]. Material properties and their effects on the moving plates/threat interactions were investigated in [6]. Whereas, the effects of the plate thickness was analyzed in [7]. In [3], the projectile length to diameter ratio (L/D) and the plate properties influencing the mitigation mechanisms were tested experimentally. It was concluded that the duration of interactions between the projectile and plate was longer for plates in motion than for stationary ones. A range of fragmentation increased with the plate velocities, with a decreasing length to diameter ratio $\mathrm{L} / \mathrm{D}$ of the projectile and with increasing thickness of the plate. It was also observed that the $\mathrm{L} / \mathrm{D}$ ratio of the projectile influenced mainly the rotation of the projectile. A decrease in length of the projectile after traversing the disturber was almost independent of the initial length of the projectile. Reduction of velocity in the launch direction decreased with the increasing L/D. For the plates moving forwards, however, the projectile fragmentation depended on the projectile velocity. It was noticed that at the lowest and highest velocities (1500 and $2500 \mathrm{~m} / \mathrm{s}$ ) the projectile broke into many parts, while at the intermediate velocity $(2000 \mathrm{~m} / \mathrm{s})$, it was almost undamaged.

As the threat in the given study, tungsten heavy alloy Y925 KE projectiles are used. In the experimental campaign, the down-scaled rods are shot against targets but their factor $\mathrm{L} / \mathrm{D}=$ 20 is the same as for threats used to evaluate the protection level, according to the standard STANAG 4559 [8]. 
Several configurations with the natural rubber interlayer of different thicknesses are prepared and tested against the KE projectiles with the impact velocity above $1500 \mathrm{~m} / \mathrm{s}$. Due to a multi-flash X-ray radiography, several images depicting the threat and target behavior in different time steps are obtained allowing observations of the defeat mechanism. The experimental results are then completed by a numerical simulation in the Ls-Dyna explicit code, which provides an analysis of the experimentally observed deformation and fracturing of the proejctiles and targets. The study proves the protective efficiency of the presented passive armor concept and explains the performance of an armor that uses the mechanism of bulging to mitigate kinetic-energy penetrators.

\section{TEST CONFIGURATION}

High costs of full-scale ballistic tests inspire experimental works with laboratory, down-scaled models. The dimensions are reduced but the geometrical proportion and material properties of a tested threat/target configuration are the same as in the full-scale test. Additionally, wellequipped academic laboratories provide often more detailed measurements and observations than it is possible at open-field proving-ground sites, where full-scale models are tested. In the experimental campaign discussed here, the long-rod projectiles have the diameter of $4 \mathrm{~mm}$ and the length of $80 \mathrm{~mm}$ resulting in the length/diameter (L/D) ratio of 20, Fig. 1.

To a shot, a KE projectile is inserted in a plastic sabot, which stabilizes the projectile in a barrel and during the first flight phase. The sabot's mass is $19.4 \mathrm{~g}$ and the mass of the KE projectile made with the tungsten alloy Y925 is $19.1 \mathrm{~g}$. The total mass of the KE projectile in the sabot is $38.5 \mathrm{~g}$. The aluminum cup stabilizes the rod during a flight without affecting its behavior while target penetration.

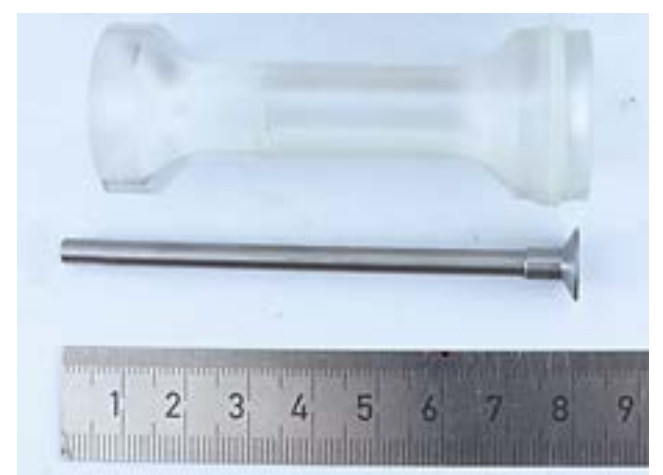

Figure 1: Down-scaled KEP with L/D = 20 and its sabot. 


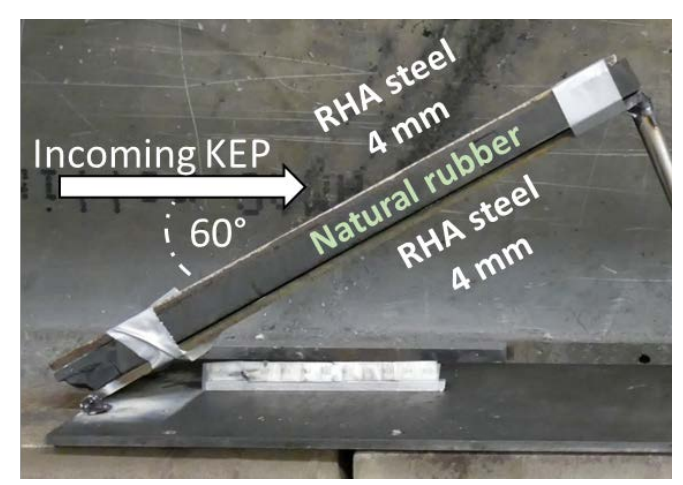

Figure 2: Bulging armor configuration inclined at $60^{\circ} \mathrm{NATO}$.

It is still argued whether down-scaled equivalents of KE projectiles represent correctly the behavior of threats and targets during a battlefield impact. It is not fully clear if a geometric scaling alters experimental results, [9-11]. Two-dimensional numerical simulations, presented in [11], have shown that the strain-rate sensitivity of the flow stress in the target material can cause some non-scaling effects in the penetration depths of long-rods. However, with wellestablished material properties for a steel, a numerical model resulted in a $5 \%$ difference in penetration depth for a full scaled versus a 1:10 scale problem. This difference is small enough to be neglected in most practical cases.

\subsection{Composition of the targets}

For the shots, the targets are inclined at $60^{\circ}$ NATO, Fig. 2. In the down-scaled configuration, the targets have the size $40 \times 200 \mathrm{~mm}$. The laminates are composed by the $4 \mathrm{~mm}$ thick front steel plate - the rubber interlayer - and the $4 \mathrm{~mm}$ thick back steel plate, [12]. To allow a free expansion of the rubber layer and thus, a movement of the plates, no adhesive is used to bond the components.

The side plates are made with the rolled homogenous armor steel (RHA). The RHA armor steel grade is a high strength martensitic steel with the standardized composition (e.g. [13]) and material properties (i.e. hardness about $380 \mathrm{HB}$, UTS about $1200 \mathrm{MPa}$ ) produced by most of armor steel manufactures. An extensive discussion presented in [14-16] concerns the mechanical and material properties of an RHA steel. Based on the experimental data presented in [16], the flow curves at the quasi-static and dynamic (4800 s-1) strain rates characterizing the RHA grade steel are given in Fig. 3(a).

In the hereby discussed approach, natural rubber with different thicknesses is chosen to evaluate the behavior of the elastomeric interlayer in the protection system. The natural rubber used in the presented test configuration is characterized by the hardness 70 Shore (scale A) and the tensile strength of $25 \mathrm{MPa}$ at the maximal elongation reaching 700\% [17]. The set of curves characterizing a natural rubber according to the classical Yeoh study [18] is given in Fig. 3(b). 


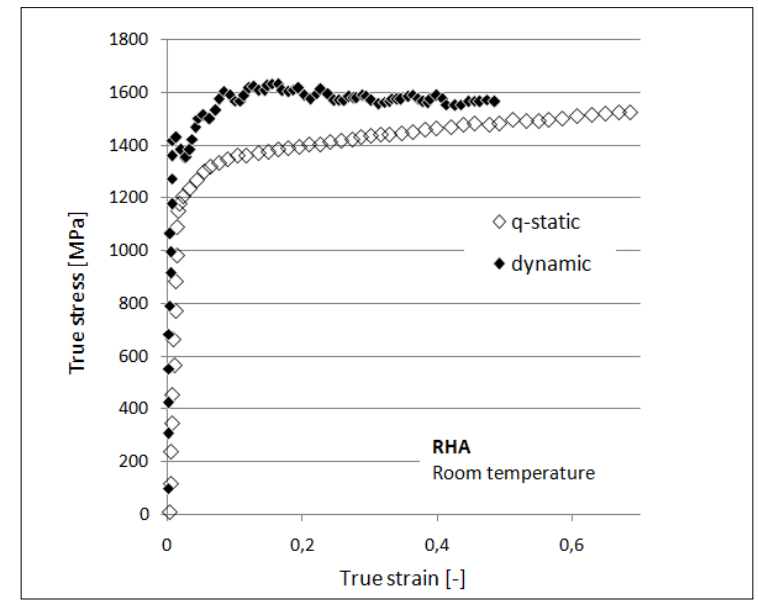

(a)

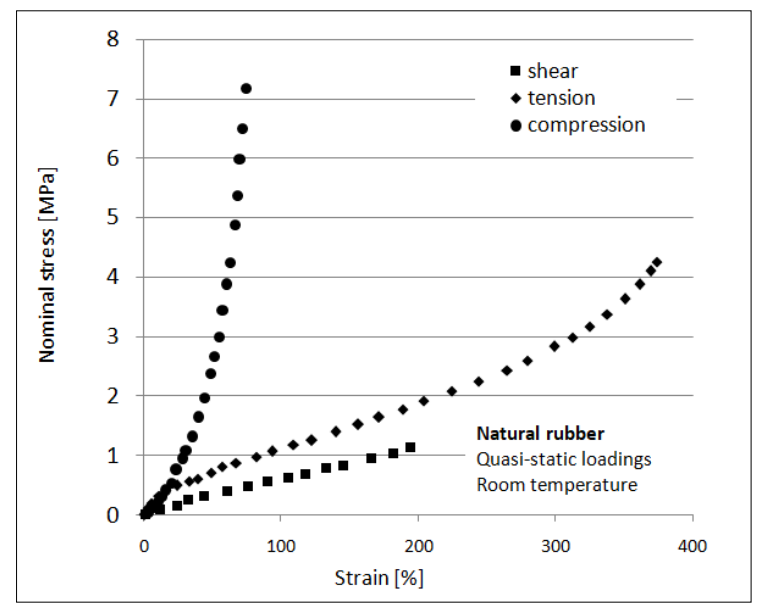

(b)

Figure 3: (a) Quasi-static and dynamic flow curves of an RHA steel [16], (b) quasistatic curves of natural rubber [20]. 


\subsection{Projectiles}

A combination of tungsten (wolfram) properties - resistance to high temperatures, hardness, density and strength, make it an important raw metal for the military industry. More than half of the extracted tungsten is consumed for the production of tungsten carbide alloys, [19]. A large part of raw tungsten is compounded with cobalt and nickel and known as tungsten heavy alloys (WHA). Less than $10 \%$ of raw tungsten is used in other chemical compounds. Tungsten heavy alloys are two-phase composites consisting of about $90 \%$ pure tungsten in a matrix of nickel, iron and cobalt. Addition of these elements improves the ductility and machinability of the non-alloyed tungsten. In consequence, the WHA alloys are characterized by a unique combination of high density, high strength, moderate hardness and ductility, moderate electrical and thermal conductivity and good corrosion resistance, [20]. The WHA alloys are produced by powder-metal and sintering processes since the consolidation of pure tungsten (density $19.3 \mathrm{~g} / \mathrm{cc}$ ) requires excessively high temperatures. During sintering, low melting additives form a liquid and the material thickens rapidly to form a fully dense two-phase structure.

Table 1: Tungsten WHA Y925 material properties.

\begin{tabular}{|c|c|c|c|}
\hline \multicolumn{4}{|c|}{ WHA grade Y925 } \\
\hline Tungsten 92.5\% & Nickel & Iron rest & Cobalt \\
\hline $\mathrm{De}$ & & & \\
\hline Har & & & \\
\hline Tensile & & & \\
\hline Yield & & & \\
\hline Elonga & & & \\
\hline
\end{tabular}


In the current investigation, the WHA known under the grade name Y925 (prod. Kennametal Mistelgau) is used to manufacture the KE projectiles. In this alloy grade, dissolved tungsten grains are embedded in the matrix consisting of nickel, iron and cobalt; tungsten is $92.5 \%$ of the total element contain. Some properties of the Y925 WHA alloy, quoted after the producer datasheet, are presented in Table 1, [21].

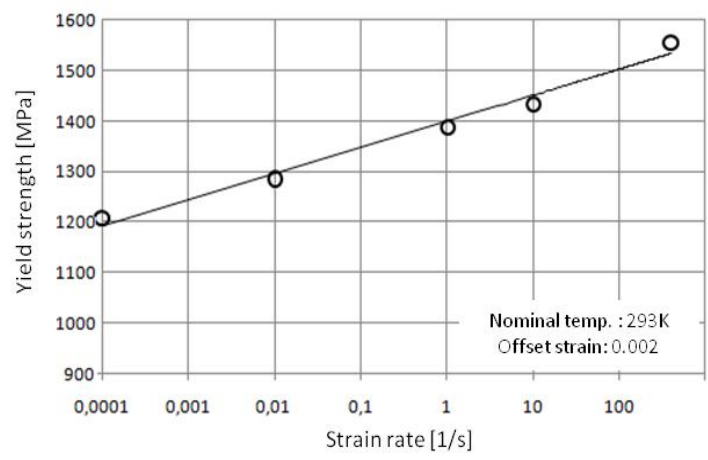

(a)

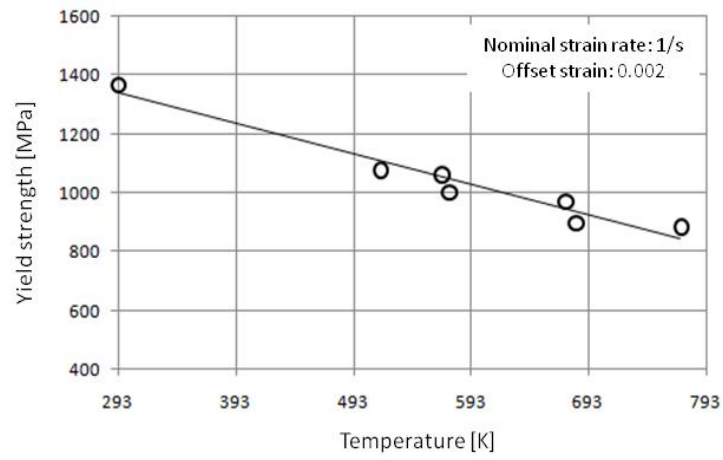

(b)

Figure 4: Tungsten heavy alloy Y925: (a) strain rate and (b) temperature sensitivity. Based on [22-23]. 
This particular alloy, WHA Y925, is present on the market for decades and has been described in several studies regarding its mechanical and ballistic behavior. In the references [22-23], there are given results of material tests on the grade Y925 of the Kennametal Mistelgau production, the same alloy which is investigated in the present study. In Fig. 4, the effects of the increasing strain rate and temperature on the flow behavior of the WHA Y925 grade are presented. At quasi-static conditions, the linear elastic behavior of the Y925 WHA grade ends up about $1300 \mathrm{MPa}$. The Young modulus determined by the authors is equal to $347 \mathrm{GPa}$ and the ultimate tensile stress for 12 tested samples varies between 1292 and $1400 \mathrm{MPa}$, with the average $1343 \mathrm{MPa}$.

\section{EXPERIMENTAL INVESTIGATION}

The down-scaled projectiles described in the previous section are inserted in sabots and launched by a powder gun cal. 25. During the impact test, the initial velocity is measured by a light barrier. Each shot is recorded by a multi-anode flash X-ray radiography, which follows the projectile trajectory from the side view. In the case of high-velocity KEP impacts, it is difficult to extract residual fragments of projectiles after the shot. The X-ray radiography captures interactions between the threat and target during a shot and these images are often the only evidence of the experimental investigation. The X-ray radiography available at the ISL laboratory provides six separated flash radiographs taken at different time steps, Fig. 5.

The rubber expands and shrinks during the KEP penetration of the laminate, which is well captured by the images presented in Fig. 5. The expanding rubber causes bending of the steel plates, which were initially parallel and after the perforation, they are bent in opposite directions. The configuration of two $4 \mathrm{~mm}$ thick RHA steel plates with a $15 \mathrm{~mm}$ air gap is considered as the reference aimed to show effects of the rubber application. Then, the steel plates sandwich the rubber layers with different thicknesses $(5 \mathrm{~mm}, 10 \mathrm{~mm}, 15 \mathrm{~mm}$ and 2 times $10 \mathrm{~mm}$ ). All laminates are inclined at the NATO angle $60^{\circ}$. At this obliquity, the line of sign (LOS) along which a projectile perforates the target is equal to 28, 38, 48 and $58 \mathrm{~mm}$, respectively. At the moment of impact, the rods have a velocity higher than $1500 \mathrm{~m} / \mathrm{s}$. Comparing the velocity loss measured for the configurations with different rubber thicknesses and the configuration without the rubber, it may be noticed that the interlayer does not affect greatly the residual velocity of the rod fragments. An average 5\% decrease of the rod velocity after the sandwich perforation is not significantly high to be considered as a proper defeat mechanism. However, on the flash X-ray images presented in Fig. 5, it may be seen that the rods which passed thought the steel-elastomeric laminates are fragmented. This effect does not occur when the KEP perforates the configuration without a rubber but with the air gap instead - in that case, the penetrator is undisturbed and undamaged. 


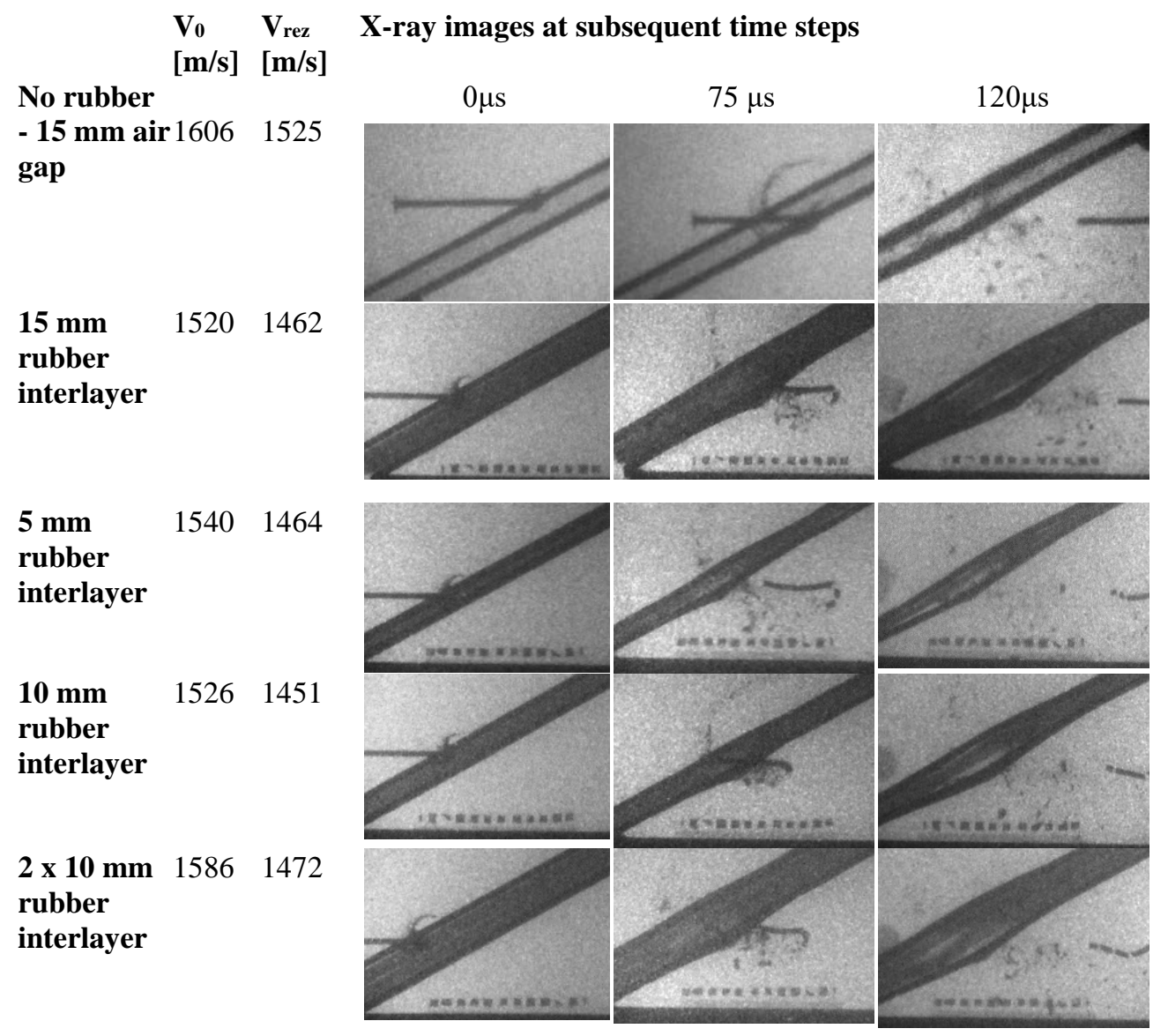

Figure 5: Experimental tests registered by the flash X-ray images (VO - initial velocity, Vrez - residual velocity).

\subsection{Bulging effect}

The bulging armors take advantage of the rubber properties. Elastomers are built up by long molecule chains that form a polymer. The raw material of natural rubber has no links between the molecule chains - they are formed during a process of vulcanization, due to which chains are connected with cross-links. Weak intermolecular forces that join chains of rubber molecules are responsible for the characteristic rubber properties, as an ability to a quick elastic deformation. Upon an impact, high pressure is transferred into the interlayer by a fastmoving striker causing rapid changes of the rubber shape. The elastomeric interlayer compresses under the projectile nose, then it expands rapidly during the penetration and finally, it bounces back to the initial shape. The side steel plates deform together with the rubber structure. The projectiles are strained between the front and rear plates deforming in the opposite directions, Fig. 6 . 
Front and back halves of the rods acquire different impulse because of a difference in the interaction time with the plates. The projectiles remain intact after the early penetration phase. The laminate is interacting longer with the backward half of the rods than with their front part, which left the armor. As it may be seen on the flesh X-ray images in Fig. 5, the KEPs are broken in the middle and the back part in consequence of this asymmetrical contact and the deformation induced by the layers of the laminate. In Fig. 6, there are collected images of the perforated target configuration with the $15 \mathrm{~mm}$ thick rubber interlayer. Because of the plates obliquity and their deformation, the holes through which the rod passed have elongated shapes. The exit hole in the rear plate is longer (in the case of the presented configuration: $18.2 \times 7.7 \mathrm{~mm})$ than the entry hole $(13.8 \times 7.6 \mathrm{~mm})$, Fig. 6(a-b). Cracks torn the rubber starting from the perforation hole of a shape similar to that observed in the steel plates $(25.2 \times 8.2 \mathrm{~mm}$, Fig. 6(c)).

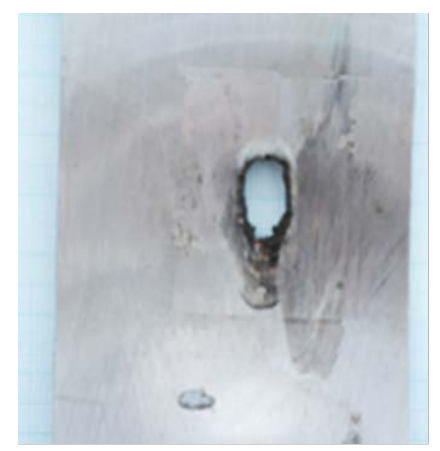

(a)

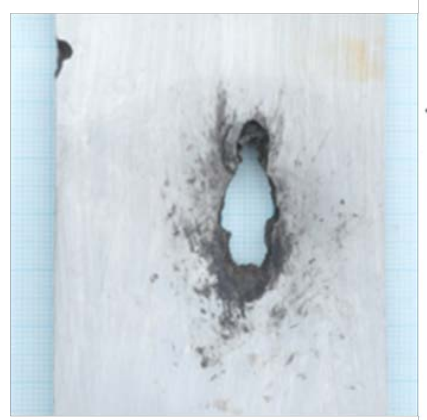

(b) 


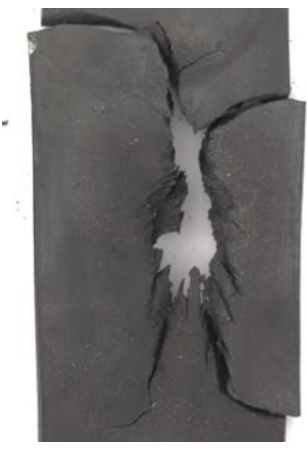

(c)

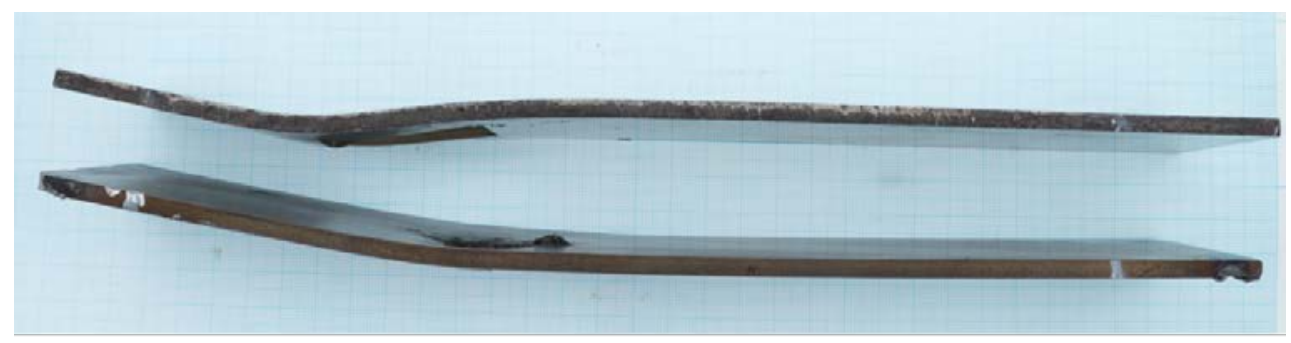

Figure 6: Target laminate after a shot: (a) entry hole - front plate face, (b) exit hole - front plate face, (c) perforated rubber - front face, (d) bent side steel plates (by an arrow the impact direction is indicated).

\section{NUMERICAL ANALYSIS}

The hereby discussed simulation is considered as a preliminary study, which objective is to show the general performance principles of the proposed armor concept and the evoked defeat mechanism. The material models for all components are literature-based, which is a common engineering approach in the first evaluation of an analyzed problem. The calculations have been performed with the explicit solver of the finite element Ls-Dyna software package v. 9.0.1.

The configuration parts are modeled as deformable Lagrangian solids. All components are discretized by reduced integration 8-node solid elements with stiffness-based hourglass control. The long-rod of the diameter and length $4 \mathrm{~mm}$ and $80 \mathrm{~mm}$, is meshed by elements of the size $0.1 \times 0.1 \times 0.1 \mathrm{~mm}$, which results in 1,192,000 elements. The plate 4 x 40 x $200 \mathrm{~mm}$ has a fine mesh of $0.1 \times 0.1 \times 0.1 \mathrm{~mm}$ in the central impacted zone $(20 \times 40 \mathrm{~mm})$, whereas a coarser meshing is applied on the plate sides - as it is presented in Fig. 7. Each plate is meshed by 441.000 elements. The rubber layer is discretized by regular elements of the size $0.2 \times 0.2$ x $0.2 \mathrm{~mm}$, which gives in total 535,464 elements for the $15 \mathrm{~mm}$ thick layer. A very fine mesh of the rod and in the direct impact zone allows modeling of thin cracks leading to fracture and fragmentation, [24-26]. 


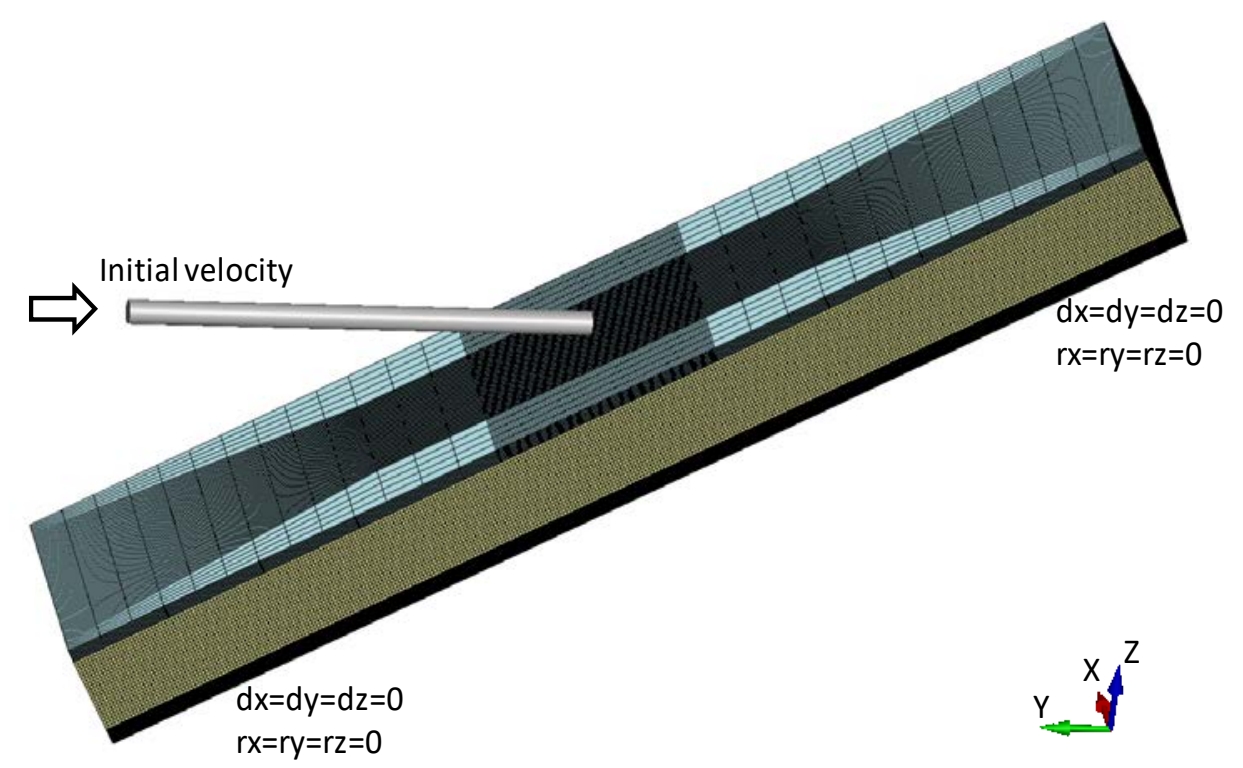

Figure 7: Target representation of the target with the $15 \mathrm{~mm}$ thick rubber interlayer.

Between the rod and the parts of the laminate, the eroding contact is applied (*ERODING_SURFACE_TO_SURFACE). Without insight into friction conditions, an assumption of the frictionless contact between all components is taken. The target parts are in contact due to the option *AUTOMATIC_SURFACE_TO_SURFACE, which represents well a free contact between the layers in the experiment. To reproduce the test boundary conditions, the sides of the laminate are fully clamped. To the rod, the initial impact velocity is assigned. The similar conditions are assumed for the configuration without the rubber interlayer and for those with the rubber of different thicknesses.

\subsection{Implemented material models}

The popular models available in many codes, and in Ls-Dyna also, are applied to describe the tested materials. For the steel and the tungsten alloy - the Johnson-Cook flow and fracture model, and for the rubber - the Ogden model is chosen.

In the reference [23], there is proposed a set of the material model constants describing the plastic hardening of the Y925 WHA according to the Johnson-Cook flow model, [27-28]. This plasticity model is implemented in many numerical codes and in numerous studies, it was proven to be a reliable approach towards modeling of dynamically deformed materials, also under impact loadings.

$$
\sigma=\left(A+B \varepsilon^{n}\right)\left(1+C \ln \frac{\dot{\varepsilon}}{\dot{\varepsilon}_{0}}\right)\left(\frac{T-T_{r}}{T_{m}-T_{r}}\right)^{m}
$$


The model takes into account phenomenological observations of the steel and metals behavior, namely influence of the strain $\varepsilon$, strain rate $\dot{\varepsilon}$ and temperature $T$ on their deformation - these three dependences are decoupled from each other in three terms. In the given equation $T_{r}$ are $\dot{\varepsilon}_{o}$ are the reference temperature and strain rate at which the coefficients $A$ and $n$ are determined. The constant $C$ in the second term takes into account the strain rate dependency and finally, in the third term $T_{m i s}$ the melting temperature for which $m$ is the parameter that represents the effect of temperature on the flow stress. The model constants obtained by the authors of [23] for the tungsten alloy Y925 are presented in Table 1.

Table 1. Parameters of the JC flow model for the WHA Y925 grade, [23].

\begin{tabular}{cc}
\hline \multicolumn{1}{c}{ WHA grade Y925 } \\
\hline $\boldsymbol{A}$ [MPa] & $1258 \pm 97$ \\
$\boldsymbol{B}$ & $0.092 \pm 0.014$ \\
$\mathbf{C}$ & 0.0013 \\
$\boldsymbol{n}$ & $0.014 \pm 0.0003$ \\
$\boldsymbol{m}$ & $0.940 \pm 0.007$ \\
\hline
\end{tabular}

The JC cumulative-damage fracture model accounts for the loading history represented by the strain to fracture $\varepsilon_{f}$. It is based on the analysis of the stress triaxiality state $\eta$ and expressed also as a function of the strain rate $\varepsilon$ and temperature T.

$$
\varepsilon_{f}=\left(D_{1}+D_{2} \exp D_{3} \eta\right)\left(1+D_{4} \ln \frac{\dot{\varepsilon}}{\dot{\varepsilon}_{0}}\right)\left(1+D_{5} \frac{T-T_{r}}{T_{m}-T_{r}}\right)^{m}
$$

The first term of the model represents the stress state influence on the strain and is predominant when compared to the other terms, which represent the influence of the temperature and strain rate at fracture. The damage evolution is described by the damage variable $\mathrm{D}$, representing the surface density of intersections of micro-cracks and micro-cavities with any plane in the body.

$$
D=\sum \frac{\Delta \varepsilon}{\varepsilon_{f}}
$$

For material in the initial state of loading $\mathrm{D}=0$ and for a material which failed $\mathrm{D}=1$. A fracture occurs when the damage parameter $\mathrm{D}$ reaches an assumed limit value.

The fracture model formulation and the discussion on it may be found in numerous works, primarily in the original papers of Johnson and Cook, [28-29]. The parameters of the flow and fracture model for the RHA steel are presented in Table 2.

Having the fracture model identified for the RHA steel allows an application of the Johnson-Cook model implemented in Ls-Dyna by the classical material card *MAT_15. This model formulation requires the equation of state (EOS), here the *EOS_GRUNEISEN card. For the steel, the parameters of the Gruneisen equation of state may be found in [29] and they are collected in Table 2. 
Table 2. Modelling of the RHA steel, [14, 29].

\begin{tabular}{cccccc}
\hline \multicolumn{2}{c}{$\begin{array}{c}\text { JC flow } \\
\text { model }\end{array}$} & \multicolumn{2}{c}{ RC fracture model } & \multicolumn{2}{c}{ Gruneisen EOS } \\
\hline $\boldsymbol{A}[\mathrm{MPa}]$ & 1193 & $\mathrm{D} 1$ & 0.21 & $\mathrm{C}$ & 4570 \\
$\boldsymbol{B}$ & 500 & $\mathrm{D} 2$ & 7.21 & $\mathrm{~S} 1$ & 1.49 \\
$\mathrm{C}$ & 0.0043 & $\mathrm{D} 3$ & -5.44 & $\mathrm{~S} 2$ & 0 \\
$\boldsymbol{n}$ & 0.67 & & & $\mathrm{~S} 3$ & 0 \\
$\boldsymbol{m}$ & 1.17 & & & $\gamma 0$ & 1.16 \\
& & & & $\boldsymbol{\rho}[\mathrm{g} / \mathrm{cm} 3]$ & 7.85 \\
\hline
\end{tabular}

\subsection{Fracture Modeling}

Shattering and fragmentation of bullet cores, penetrators or explosive rings made with high strength and hard steels/metals, which tend to crack into small pieces under a complex stress state caused by an impact, is still challenging for an exact characterization and thus, for numerical modeling. Modeling techniques used numerically are then more based on the postexperimental observations rather than on the material characterization of the damage and fracture. Fracture modeling is still performed mainly at quasi-static strain rates and the room temperature in simple stress states (like uniaxial tension, compression, shearing or even bending, shear-compression, biaxial-tension/compression...). Impact scenarios with multimaterial configurations at the high impact velocities are much more complex than it may be tested in laboratory conditions. Certain numerical techniques, like smooth-particle hydrodynamics (SPH) or node splitting, may be applied to model serious fracturing of metallic structures. Additionally, in the Ls-Dyna code [30], an option of an additional erosion criterion is available, which implements an additional fracture criterion in calculations. The software provides a choice among several options (e.g. the maximum shear strain at failure, equivalent strain at failure, minimum pressure at failure...). Such an additional criterion based on a chosen threshold may be considered as artificial or aimed for an expected final result but carefully chosen and treated with caution, an 'add-erosion' criterion may provide modeling of the material response which explains phenomena occurred during a complex fracturing.

As the material characterization, which describes the tungsten alloy Y925 does not account for characteristics of its fracture, the *MAT_SIMPLIFIED_JC (*MAT_98) is applied in the calculations. This implementation of the Johnson-Cook flow model does not describe temperature effects and is decoupled from the JC fracture model. To introduce fracturing in the modeled material, the material card has a simple fracture condition PSFAIL - the effective plastic strain at failure. Its value is set as 1.0. Additionally, the option *MAT_ADD_EROSION is active with a threshold of the minimum pressure at failure MNPRES. The pressure, i.e. the hydrostatic stress, is the average of the three normal stress components of any stress tensor:

$$
p=-\frac{1}{3} \sigma_{k k}=\frac{\sigma_{11}+\sigma_{22}+\sigma_{33}}{3}
$$

where $\mathrm{k}=1,2$, 3. According to the Ls-Dyna theory manual [30], the hydrostatic pressure in the Ls-Dyna formulation is positive in compression. 
In the fracture criterion MNPRES, when the assumed minimal value pmin is obtained, the element is deleted from the model. Several examples presented in the literature prove that calculations with that option model well fragmentation and shattering of high strength cores of small-caliber rounds upon an unsymmetrical contact with a target, [31-33].

\subsection{Rubber modeling}

Inspired by the elastomeric ability to a huge elastic extension, research on modeling of the elastomer behavior focused on a large strain tension regime. A general theory of non-linear hyper-elasticity is classically invoked to predict the material response under static loading conditions or to develop more advanced models for the visco-elasticity. Over the decades, numerous models have been proposed to describe this elastomeric feature. Traditional models are formulated in terms of a strain-energy function $\mathrm{W}$. The models are based on the assumption that there is the potential of strain energy by which the stored strain energy on the unit initial volume fraction as a function of strains is defined in the material, [34]. Among these conventional hyper-elasticity models, the Mooney model (and its generalization proposed further by Rivlin) is the oldest [35]. The Mooney function performs well only up to a moderate extension range but cannot represent the nonlinear strain-hardening typically exhibited by rubbers at a large strain level. Subsequently, many researcher (e.g. Ogden [36]) proposed improvements to cover also this range.

In the current approach, the available in Ls-Dyna formulation the Ogden model (*MAT_77) is chosen, proven many times as efficient in the modeling of hyper-elastic material behavior. In the Ogden approach, the strain energy is a function of the elongation $\lambda$ of the strain tensor. Thus, the strain energy according to the Ogden formulation is given as follow:

$$
W=\sum_{p=1}^{n} \frac{\mu_{p}}{\alpha_{p}^{2}}\left(\lambda_{1}^{\alpha_{p}}+\lambda_{2}^{\alpha_{p}}+\lambda_{3}^{\alpha_{p}}-3\right)
$$

where $\mu_{p}$ and $\alpha_{p}$ are material constants and $\mathrm{n}$ indicate an order of approximation.

The model is formulated in a power form, so to fit an experimental stress-strain data to a desired degree of precision, a sufficient number of terms may be taken. Here, a set of the model parameters for $\mathrm{n}=3$ proposed by Yeoh [39] describing a natural rubber characterized by the curves shown in Fig. 3(b) is applied, Table 3. Since the card *Mat_077 does not model material damage, the additional erosion criterion must be applied to introduce a failure in the perforated rubber. The criterion of the shear strain at failure equals 1.0 is then chosen in the card *Mat_add_erosion. 
Table 3. The Ogden model parameters for natural rubber, [18].

\begin{tabular}{ll}
\hline Natural rubber & \\
\hline Ogden model & \\
\hline$\alpha_{1} 1.3$ & $\mu_{1} 0.618$ \\
$\alpha_{2} 5.0$ & $\mu_{2} 0.00118$ \\
$\alpha_{3}-2.0$ & $\mu_{3} 0.00981$ \\
\hline
\end{tabular}

The discussed configuration consists of 3 materials (tungsten alloy, armor steel and rubber) with different material properties. An in-house material characterization might result in a more reliable and detailed numerical simulation. Nevertheless, the material models available in the literature allow also for a first evaluation and an explanation of phenomena occurred during the target-threat interaction.

\section{NUMERICAL RESULTS}

Based on the formerly described experimental investigation and the chosen material modeling, the laminate with the $15 \mathrm{~mm}$ thick rubber interlayer is analyzed numerically. The stages of penetration and the final perforation presented along the curve of the impact velocity reduction are given in Fig. 8.

\subsection{Simulation of the configuration with the $15 \mathrm{~mm}$ thick rubber interlayer}

The high impact velocity, $1500 \mathrm{~m} / \mathrm{s}$, causes the ejection of small steel debris forming a characteristic 'cloud' of a quarter-circular shape at the moment when the projectile strikes the front plate (step 1, Fig. 8). In the test recorded on the images presented in Fig. 5, a cloud of fragments is larger and denser but, in the simulation, the Lagrangian representation of the model cannot provide such an extensive separation between elements.

While the KEP pushes its way through the laminate, the rubber around the perforation channel is expanding around allowing its passage (steps 2 and 3), and then, it is returning to the initial position enfolding the rod tightly (step 3 and 4). The expansion of the rubber and the movement of the KEP cause the deformation of the front and the back steel plate (step 4). When the rod leaves the front plate, both plates are already bent in opposite directions (step 6 ). The crack initiates on the upper periphery of the projectile being in contact with the plate. The rear part of the rod is stabilized by the rubber already closed around it, whereas its front part is bent slightly down by the deformed back-plate. In the relatively brittle tungsten alloy susceptible to tension, the crack initiates easily and propagates down the rod diameter leading to the breakage of the long-rod into two pieces, Fig. 8(b). During the experiment (Fig. 5), the pictures taken at the time instant $125 \mu \mathrm{s}$, when the projectile is already about $70 \mathrm{~mm}$ behind the perforated target, visualize the separation of the fragmented rod pieces.

In the simulation, to obtain the long-rod fracturing the additional erosion criterion of the minimum pressure at failure equals to -650 MPa is applied (the hydrostatic pressure in the LsDyna formulation is positive in compression). The threshold value is chosen basing on the simulation of the same target configuration without the additional erosion criterion, discussed below. 


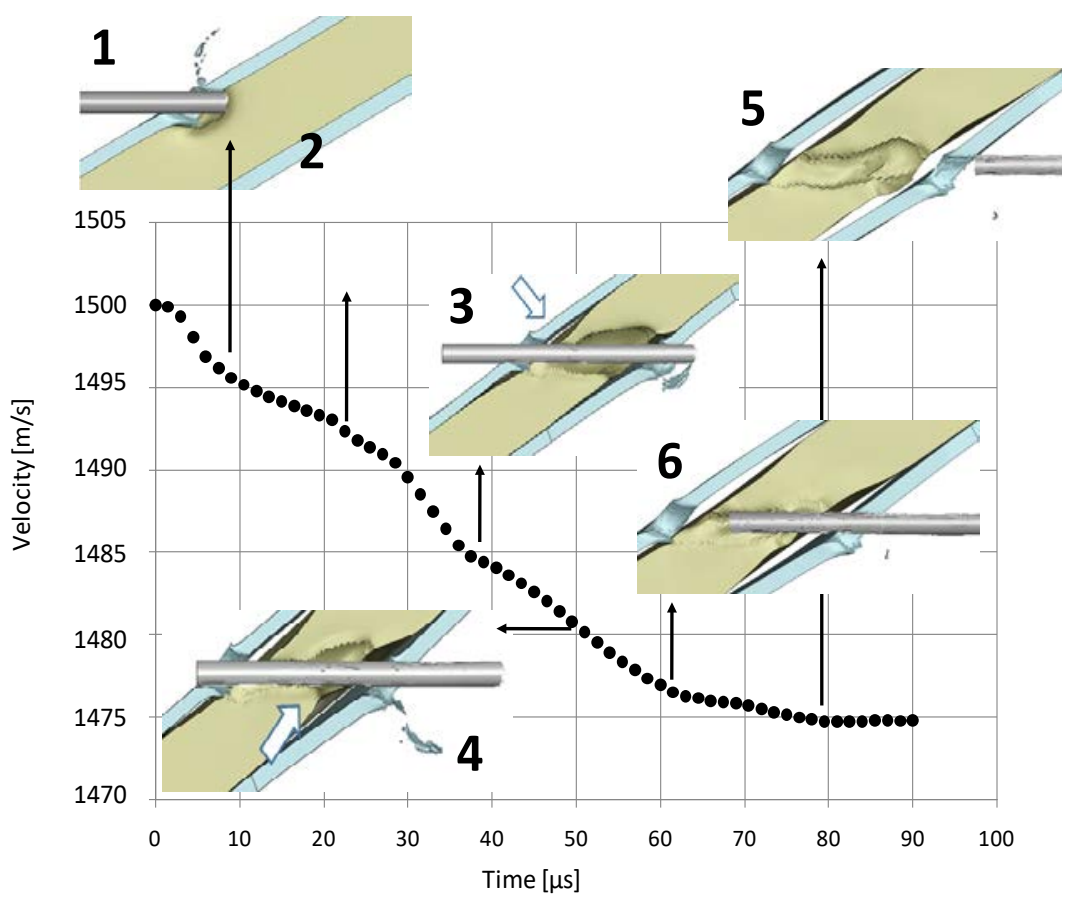

(a)

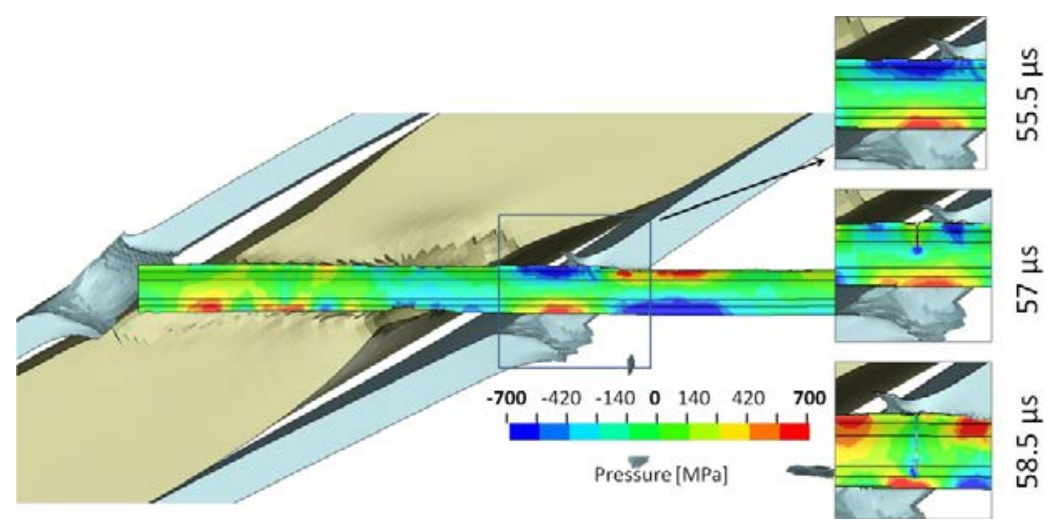

(b)

Figure 8: Penetration of the steel-elastomeric laminate: (a) impact velocity reduction and $(b)$ fracture propagation 


\subsection{Simulation without the add-on erosion criterion}

The simulation is performed on the exactly same configuration as the former one, except for the applied fracture criterion for the tungsten alloy. This time, only the failure condition available in the used material card describing the KEP is active, i.e. the effective plastic strain at failure here equals 1.0. Its application results in the projectile nose erosion because of the contact with the side steel plates. The option *Mat_add_erosion, due to which the criterion of the minimum pressure at failure is introduced to the rod in the previous calculation, is not used.

In the maps of the pressure stress, it may be observed how the long-rod deforms and bends traversing the target layers, Fig. 9a. After the laminate perforation, the deformed rod has a zlike shape (step $90 \mu \mathrm{s}$ ). There are two zones, where the KEP is stronger bent, one indicated by a filled arrow (pointing up) and then, the second one indicated by an unfilled arrow (pointing down). The simulation shows that the rear part of the rod is stabilized by the rubber (step $60 \mu \mathrm{s}$ ) which enfolds it tightly, whereas the upper periphery of the front part is in contact with the perforation hole in the back steel plate. The plate is deforming due to the rubber expansion and pushes the penetrator downwards causing its bending. In the calculation where the erosion criterion is applied, the crack initiates at the first curvature.
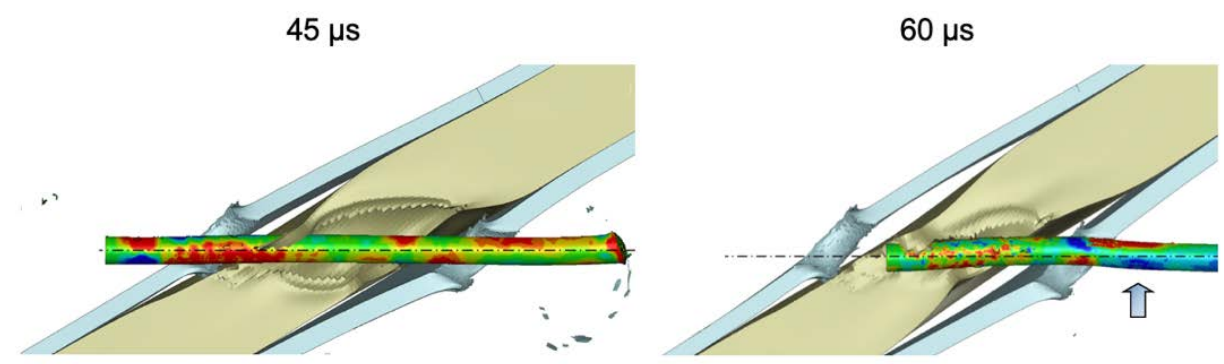

$65 \mu \mathrm{s}$

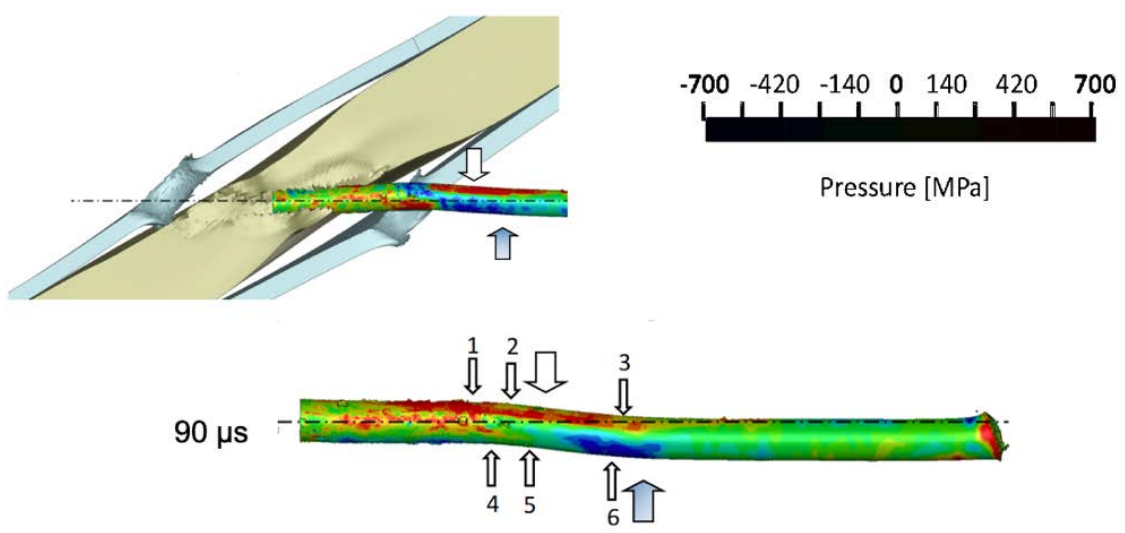

(a) 

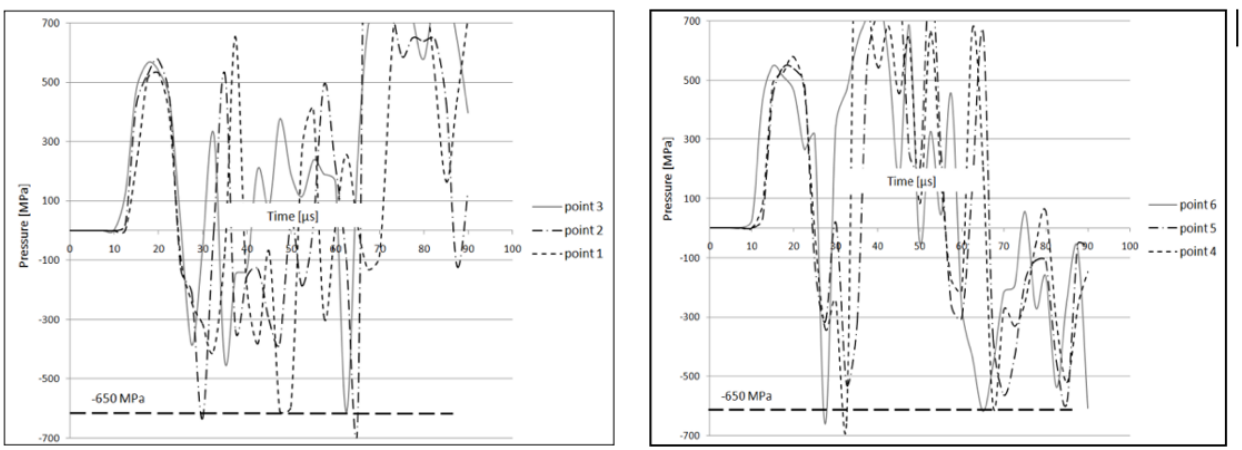

(b)

Figure 9: Simulation without the add-on erosion criterion: rod deformation, (b) pressure in time development for the points on the rod periphery.

Figure 1: Influence of various thresholds of the minimum pressure at failure on the rod fragmentation.

\section{Minimum \\ Resulted rod fragmentation \\ pressure at}

failure:

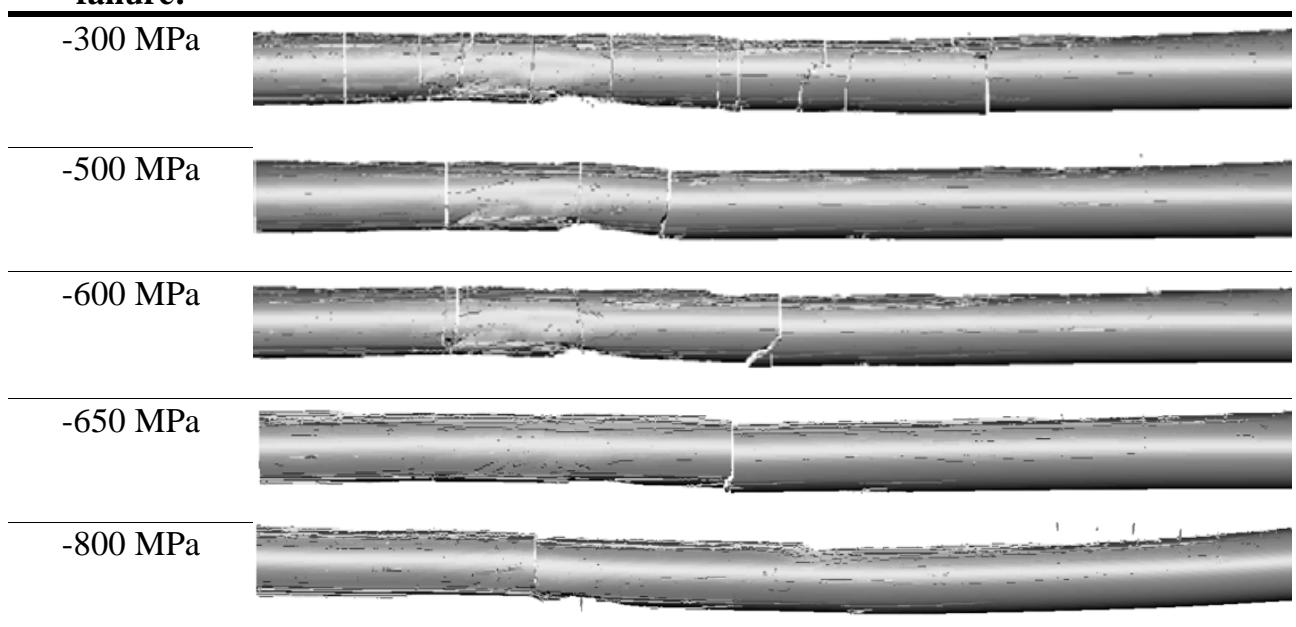

To identify a range of the pressure which occurs in the deformed rod, six arbitrary points in the proximity of two bent zones are chosen (Fig. 9a, time step $90 \mu \mathrm{s}$ ). The relevant dependences of the pressure in time are presented in Fig. 9b. The minimal calculated pressure reached $-700 \mathrm{MPa}$, on average the minimum pressure peaks are about $-650 \mathrm{MPa}$, and this value is chosen as the threshold in the add-on fracture criterion. 


\subsection{Parametric study on different values of the minimum pressure at failure and the resulted long-rod fragmentation}

An analysis of the stress state provided a suitable minimal pressure threshold to obtain the long-rod fracturing, which mimics the experimental observations. However, the fragmentation depends on the chosen value of the minimum pressure at failure. In Fig. 10, there is presented a parametric study on different fracture limits that shows a range of the rod fragmentation in dependence on the threshold value. The meshing of the striker is very fine (the size of the elements is $0.1 \mathrm{~mm} 3$ ), the modeled crack contains only a single elements layer. A too high value of the erosion criterion results in too severe fracturing, which does not represent well the tests observations. It is the case when the minimum pressure equals to $-300 \mathrm{MPa}$. When this value is decreased to $-800 \mathrm{MPa}$, the KE penetrator breaks in two parts but its front part is slightly bent and longer compared to the rear one. A lower value would not allow for crack initiation at all. The study shows that the cracking of KEP is sensitive to a value of the minimum pressure, which should be chosen carefully.

The question should be stated if it is necessary to apply an additional fracture criterion. The classical function of the Johnson-Cook fracture model is relatively simple e.g. [37-38] and does not cover all sensitivities of the critical stress states, which lead to material failure. High strength metals are usually sensitive to tensile stresses and tend to fracture overloaded in that regime. Under this assumption, an application of the minimal pressure at failure may be then favored. When the assumed limit value of the criterion defined according to Eq. (4) is reached, the fracture condition is fulfilled and the element is deleted from the mesh. This simplified and based on the phenomenological observations approach allows modeling of the tungsten rod fracturing, which represents the experimental observations and is not inconsistent with the physics of the material.

\subsection{Simulation of the laminates with different rubber thicknesses}

In the subsequent simulation, the configuration without the rubber is modeled numerically. The material models, fracture criteria are used exactly as in the simulation of the configuration with the $15 \mathrm{~mm}$ thick rubber interlayer. The results are presented in Fig. 10(a). While the projectile passes through the steel plates, its nose erodes due to the contact with them. However, without the rubber interlayer, the bending of the rod does not occur, neither its fracture. In the numerical simulation, the deformation which the projectile undergoes during the penetration of two steel plates is not sufficient that the minimum pressure at failure fracture condition, applied also here, was activated.

Even if the numerical fragmentation of the long-rods is not identical with the results of the test, the simulation captures correctly differences in the influence of the different rubber layers on the projectile behavior, Fig. 10. According to the calculations, the maximal deformation of the laminate (the widest distance between two plates) increases with the rubber thickness. In the case of the laminate with the $5 \mathrm{~mm}$ thick rubber interlayer, its thickness (initially $14 \mathrm{~mm}$ ) increases to $17.3 \mathrm{~mm}$. Respectively for the other targets - with the $10 \mathrm{~mm}$ rubber layer to 22.7 $\mathrm{mm}$ (the initial thickness $18 \mathrm{~mm}$ ), with the $15 \mathrm{~mm}$ thick rubber to $27.7 \mathrm{~mm}$ (the initial thickness $23 \mathrm{~mm}$ ) and with the $20 \mathrm{~mm}$ thick rubber layer to $34.1 \mathrm{~mm}$ (initially $28 \mathrm{~mm}$ ). 

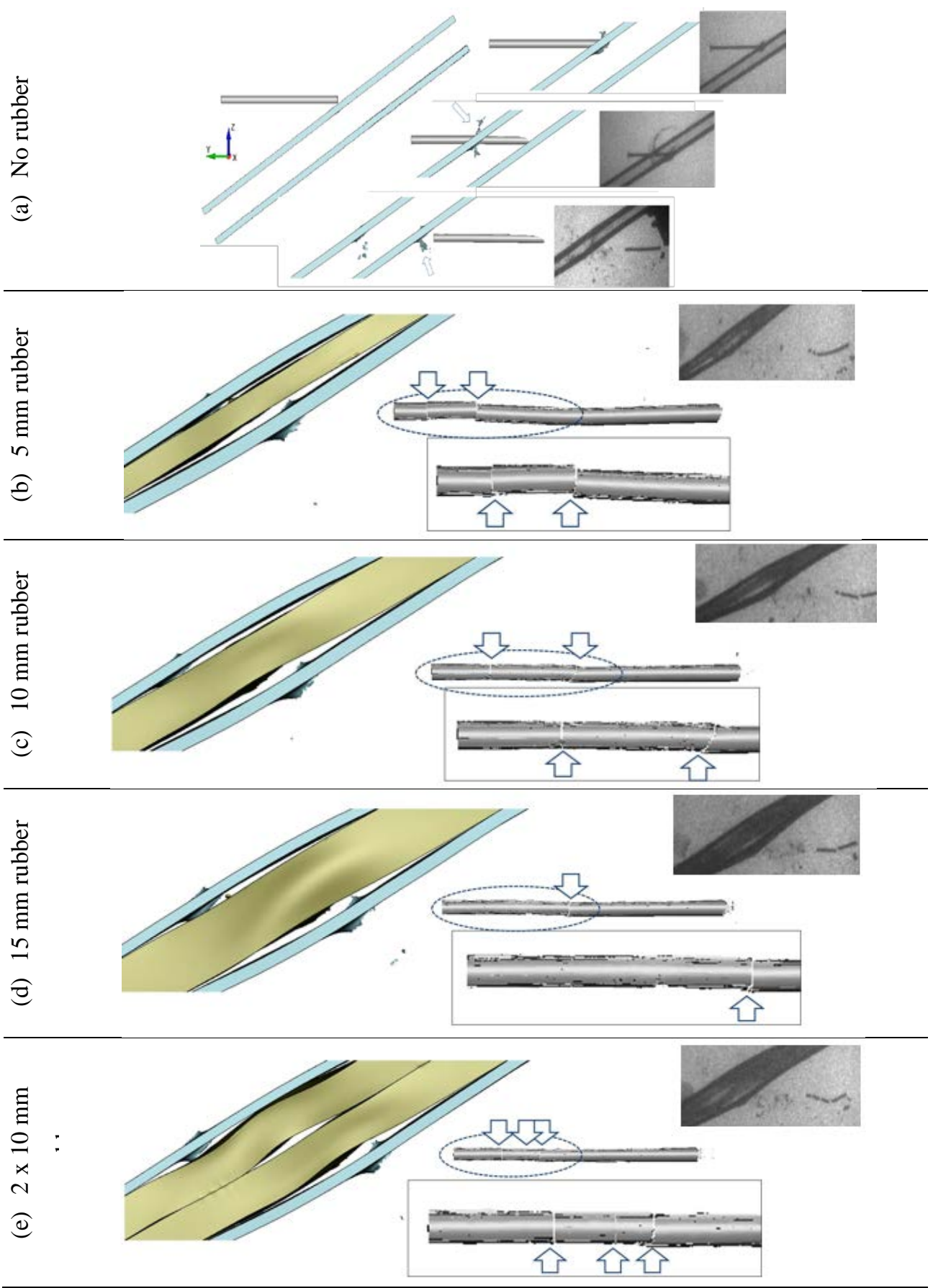

Figure 11: Influence of the rubber thickness on the rod fragmentation - numerical and experimental results. 
The simulation shows that the $10 \mathrm{~mm}$ and $15 \mathrm{~mm}$ thick rubbers cause a similar deformation of the steel plates but the rod is more fractured due to the contact with the $5 \mathrm{~mm}$ thinner laminate. Thus, it may be considered as more efficient. Like in the experiment, the thinnest laminate with the $5 \mathrm{~mm}$ rubber blocks between its layers only the last part of the penetrator, which causes its separation from the longer, slightly bent front part. Both the simulation and the experiment show that the double rubber layer causes the strongest fragmentation of the KEP - it breaks into four pieces. Each rubber layers deforms independently from another, which strengthens the bending of the side steel plates.

\section{CONCLUSION}

Based on the presented experimental and numerical investigation, the influence of a steelelastomer armor on kinetic-energy penetrators is discussed. In the presented protection concept, the bulging effect is considered as the main defeat mechanism leading to an efficient minimization of the piercing potential of KEPs. Hit by a long-rod projectile with high impact velocity, the rubber deforms rapidly causing also a deformation of the side steel plates. The rod disturbed by the plates deforming in the opposite directions starts to bend and because it is long, slender and made with a high-strength tungsten alloy of a relatively low ductility, it tends to fracture more easily when strained at tension.

The ballistic impact test concerns the down-scaled kinetic-energy penetrators ( $\mathrm{L} / \mathrm{D}=20$, rod diameter $\mathrm{D}=4 \mathrm{~mm}$ ) shot against four configurations with the rubber interlayer of different thicknesses (5, 10, 15 and $2 \times 10 \mathrm{~mm}$ ) and the configuration with an air gap instead of the rubber. The separated flash X-ray images show the KEP fragmentation and the deformation of the target layers during their penetration. Among the tested configurations, the most efficient - i.e. leading to the most serious rod fragmentation, is the configuration with the double rubber layer.

The numerical simulation performed in the Ls-Dyna Lagrangian approach adds a complementary, detailed analysis of the experimental campaign. The simulation depicts accurately the process of the rubber shape changes and its influence on the deformation of the plates. It is described how a crack initiates in the KE penetrator evoked by bulging of the steel plates. The parametric study on the applied fracture criterion shows a sensitivity of the resulted rod fragmentation to the threshold of the minimal pressure at fracture, proving that a careful analysis should proceed a choice of the fracture description.

The presented study may be considered as one of the rare studies, which due to the observation technique of the multi-anode flash X-ray radiography used in the experiment and the performed numerical simulation, analyses the passive bulging armors applied against kinetic-energy penetrators.

\section{ACKNOWLEDGEMENTS}

Mr N. Faderl is gratefully acknowledged for operating the X-ray apparatus and Mr S. Gaisser is thanked for performing the ballistic test. 


\section{REFERENCES}

[1] Chiyo D, Kodandaramaiah SB, Grosh K, Ma ZD, Raju B, Rostam-Abadi F. Reactive Structure and Smart Armor for Army's Future Ground Vehicles. ARMY TANK AUTOMOTIVE RESEARCH DEVELOPMENT AND ENGINEERING CENTER WARREN MI; 2010 Dec 1.

[2] Lidén E, Mousavi S, Helte A, Lundberg B. Deformation and fracture of a long-rod projectile induced by an oblique moving plate: Numerical simulations. International journal of impact engineering. 2012 Feb 1;40:35-45.

[3] Lidén E, Andersson O, Lundberg B. Deformation and fracture of a long-rod projectile induced by an oblique moving plate: Experimental tests. International journal of impact engineering. 2011 Dec 1;38(12):989-1000

[4] Lidén E, Helte A. The break-up tendency of long rod projectiles. Defence technology. 2016 Apr 1;12(2):177-87.

[5] Lidén E, Johansson B, Lundberg B. Effect of thin oblique moving plates on long rod projectiles: A reverse impact study. International journal of impact engineering. 2006 Oct 1;32(10):1696-720.

[6] Rosenberg Z, Dekel E. On the role of material properties in the terminal ballistics of long rods. International journal of impact engineering. 2004 Aug 1;30(7):835-51.

[7] Hohler V, Schneider E, Stilp AJ, Tham R. Length and velocity reduction of high density rods perforating mild steel and armor steel plates. InProc 4th International Symposium on Ballistics, Monterey, CA, USA 1978 Oct 17 (Vol. 1).

[8] NATO AEP-55 STANAG 4569 - Protection levels for Occupants of Logistic and Light Armoured Vehicles.

[9] Anderson Jr CE, Mullin SA, Kuhlman CJ. Computer simulation of strain-rate effects in replica scale model penetration experiments. International journal of impact engineering. 1993 Jan 1;13(1):35-52..

[10] Magness Jr L, Leonard W. Scaling issues for kinetic energy penetrators. Proc. 14th Int. Syrup. on Ballistics. 1993 Sep;2:281.

[11] Rosenberg Z, Kreif R, Dekel E. A note on the geometric scaling of long-rod penetration. International journal of impact engineering. 1997 Mar 1;19(3):277-83.

[12] Hunkler R. Untersuchungen zur Wechselwirkung von Stahl-Gummi-Stahl-Sandwiches mit KE-Penetratoren. ISL Report PU 313/1993.

[13] MIL-DTL-12560J (2009-07-24). Armor Plate, Steel, Wrought, Homogeneous (for Use in Combat-Vehicles and for Ammunition Testing.

[14] Jutras M. Improvement of the characterization method of the Johnson-Cook model. Master Thesis, Québec, Université Laval 2006.

[15] Gailly B. Etude du comportement dynamique et de la rupture de trois aciers à blindage. Doctoral Thesis. Paris, ENMP, 1996. 
[16] Nahme H, Lach E. Dynamic behavior of high strength armor steels. Le Journal de Physique IV. 1997 Aug 1;7(C3):C3-373

[17] Timcorubber https://www.timcorubber.com/rubber-materials/natural-rubber [Accessed 07.05.2020].

[18] Yeoh OH. Hyperelastic material models for finite element analysis of rubber. J Nat Rubbber Res 1997;12:142-53.

[19] Leal-Ayala DR, Allwood JM, Petavratzi E, Brown TJ, Gunn G. Mapping the global flow of tungsten to identify key material efficiency and supply security opportunities. Resources, Conservation and Recycling. 2015 Oct 1;103:19-28.

[20]Bose A, Sadangi R, German RM. A review on alloying in tungsten heavy alloys. Supplemental Proceedings: Materials Processing and Interfaces. 2012 Mar 17;1:453-65.

[21] Kennametal Mistelgau. Tungsten WHA Y925 Material Datasheet.

[22] Skoglund P. Constitutive modelling of a tungsten heavy metal alloy. InJournal de Physique IV (Proceedings) 2003 Sep 1 (Vol. 110, pp. 207-212). EDP sciences

[23] Skoglund P. Constitutive modelling and mechanical properties of a tungsten heavy metal alloy. Scientific report. Weapons and Protection SE-147 25 Tumba. Foi-R—0723—SE 2002 ISSN 165-1942.

[24] Fras T, Colard L, Pawlowski P. Perforation of aluminum plates by fragment simulating projectiles (FSP). The International Journal of Multiphysics. 2015 Sep 30;9(3):267-85.

[25] Fras T, Roth CC, Mohr D. Dynamic perforation of ultra-hard high-strength armor steel: Impact experiments and modeling. International Journal of Impact Engineering. 2019 Sep 1;131:256-71

[26] Fras T, Roth CC, Mohr D. Application of two fracture models in impact simulations. Bulletin of the Polish Academy of Sciences. Technical Sciences. 2020;68(2).

[27] Johnson GR, Cook WH. A constitutive model and data for metals subjected to large strains, high strain rates and high temperatures. InProceedings of the 7th International Symposium on Ballistics 1983 Apr 19 (Vol. 21, No. 1, pp. 541-547).

[28] Johnson GR, Cook WH. Fracture characteristics of three metals subjected to various strains, strain rates, temperatures and pressures. Engineering fracture mechanics. 1985 Jan 1;21(1):31-48.

[29] Steinberg DJ. Equation of state and strength properties of selected materials. 1996.

[30] Hallquist JO. LS-DYNA theory manual. Livermore Software Technology Corporation 2006.

[31] Kılıç N, Ekici B. Ballistic resistance of high hardness armor steels against $7.62 \mathrm{~mm}$ armor piercing ammunition. Materials \& Design. 2013 Feb 1;44:35-48.

[32] Fras T, Murzyn A, Pawlowski P. Defeat mechanisms provided by slotted add-on bainitic plates against small-calibre $7.62 \mathrm{~mm} \times 51$ AP projectiles. International Journal of Impact Engineering. 2017 May 1;103:241-53.

[33] Fras T, Szachogluchowicz I, Sniezek L. Ti6Al4V-AA1050-AA2519 explosively-cladded plates under impact loading. The European Physical Journal Special Topics. 2018 Sep 1;227(1-2):17-27.

[34] Mooney M. A theory of large elastic deformation. Journal of applied physics. 1940 Sep;11(9):582-92 
[35] Rivlin RS. Large elastic deformations of isotropic materials IV. Further developments of the general theory. Philosophical Transactions of the Royal Society of London. Series A, Mathematical and Physical Sciences. 1948 Oct 5;241(835):379-97.

[36] Ogden RW. Large deformation isotropic elasticity-on the correlation of theory and experiment for incompressible rubberlike solids. Proceedings of the Royal Society of London. A. Mathematical and Physical Sciences. 1972 Feb 1;326(1567):565-84.

[37] Fraś T, Nowak Z, Perzyna P, Pecherski RB. Identification of the model describing viscoplastic behaviour of high strength metals. Inverse Problems in Science and Engineering. 2011 Jan 1;19(1):17-30.

[38] Pęcherski RB, Nalepka K, Frąś T, Nowak M. Inelastic flow and failure of metallic solids. Material effort: study across scales. InConstitutive Relations under Impact Loadings 2014 (pp. 245-285). Springer, Vienna.

[39] T. Fras. Modeling of Failure Resulting from High-Velocity Ballistic Impact. In: Handbook of Damage Mechanics: Nano to Macro Scale for Materials and Structures ed. G.Z. Voyiadijis. Springer Science + Business Media, LLC, part of Springer Nature 2020. 
